\title{
CULTURA, PATRIMÔNIO IMATERIAL E SEDUÇÃO NO ARRAIAL DO PAVULAGEM, BELÉM (PA), BRASIL
}

\author{
Dula Maria Bento de Lima (Unama) \\ Estélio Gomberg (Uesc)
}

Este trabalho identifica modalidades de práticas e de saberes que conformam o universo identitário cultural da Amazônia expressadas nos arrastões do Arraial do Pavulagem, visando apreender suas preservações e reconfigurações sociais.

PATRIMÔNIO IMATERIAL, IDENTIDADE CULTURAL, SUSTENTABILIDADE, EDUCAÇÃO.

LIMA, Dula Maria Bento de; GOMBERG, Estélio. Cultura, patrimônio imaterial e sedução no Arraial do Pavulagem, Belém (PA), Brasil. Textos escolhidos de cultura e arte populares, Rio de Janeiro, v.9, n.2, p. 53-67, nov. 2012. 


\section{CULTURE, INTANGIBLE HERITAGE AND THE SEDUCTION OF THE ARRAIAL DO PAVULAGEM, BELÉM (PA), BRAZIL}

Dula Maria Bento de Lima (Unama)

Estélio Gomberg (Uesc)

This work identifies the modalities of practices and knowledge that constitutes Amazon's universe of cultural identity expressed in the flash mobs in Arraial do Pavulagem in order to grasp its preservations and social reconfigurations.

CULTURAL IDENTITY, SUSTAINABILITY, EDUCATION, INTANGIBLE HERITAGE.

LIMA, Dula Maria Bento de; GOMBERG, Estélio. Cultura, patrimônio imaterial e sedução no Arraial do Pavulagem, Belém (PA), Brasil. Textos escolhidos de cultura e arte populares, Rio de Janeiro, v.9, n.2, p. 53-67, nov. 2012. 


\section{DE VOLTA AO COMEÇO: DO SHOW DA BANDA AOS ARRASTÕES}

Em 1987, motivados não apenas por valorizar e divulgar a música de raízes amazônicas, mas fundamentalmente por estabelecer uma forma de aproximação da banda Arraial do Pavulagem com o público, os músicos da formação inicial do grupo passaram a levar, aos domingos, a alegoria de um boizinho na tala ${ }^{1}$ para o centro de um palco improvisado na frente do Teatro Waldemar Henrique, na Praça da República, em Belém. Lá, quando a curiosidade juntava o público, eles tocavam e cantavam em show aberto a quem desejasse assistir. Dessa forma nasceu o embrião dos hoje famosos Arrastões do Pavulagem. A resposta à iniciativa foi muito maior do que eles pretenderam. Toda tarde de domingo a praça ficava apinhada de espectadores para ouvir e dançar ao som da banda. Ronaldo Silva, um dos músicos, sentiu a necessidade de aprofundar o trabalho deles, e começou a incursionar pelos interiores do Pará pesquisando música de raiz, sons, ritmos, confecção de instrumentos próprios de determinados contextos, como, por exemplo, o carimbó. Com o tempo, juntaram-se bailarinos que investigaram as coreografias de ritmos pararenses - carimbó, siriá, lundu, xote marajoara, retumbão, samba do cacete, entre outros. Em processo etnográfico, registravam, aprendiam. O movimento foi tomando vulto, e os shows das tardes de domingo evoluíram para o Arrastão Junino, realizado nos quatro domingos do mês de junho, revitalizando a roda de boi. No primeiro domingo, o cortejo chega pelo rio. Um barco tradicional da região sai do trapiche da Praça Princesa Isabel, no bairro da Condor, e navega pela orla da cidade pela Baía do Guajará, trazendo, além do boi Pavulagem - já não mais um boi de tala, mas um boi-bumbá tradicional -, o mastro de são João, que é levado em cortejo da Escadinha do Cais do Porto até a Praça da República, onde é fincado, dando início à quadra junina (figuras 1 a 3). Nos demais domingos o cortejo se repete, com o Batalhão da Estrela (banda integrada pelos músicos formados pelo Arraial do Pavulagem), os integrantes fiéis do movimento, e milhares de simpatizantes que muito agregam ao evento. Cerca de 26 mil pessoas acompanham cada arrastão, subindo a Avenida Presidente Vargas até o cruzamento com a Rua Osvaldo Cruz. Num carro de som que vai à frente, um animador vai contextualizando os elementos presentes naquele universo. Na sequência, alas de brincantes que se organizam espontanemente em ordem de chegada: os cavalinhos e boizinhos que as crianças assumem; os estandartes dos santos empunhados geralmente pelas senhoras mais velhas do grupo, os brincantes, os músicos, os bois - Pavulagem, Malhadinho, Urube e outros convidados (quase sempre os tradicionais dos bairros de Belém), os 


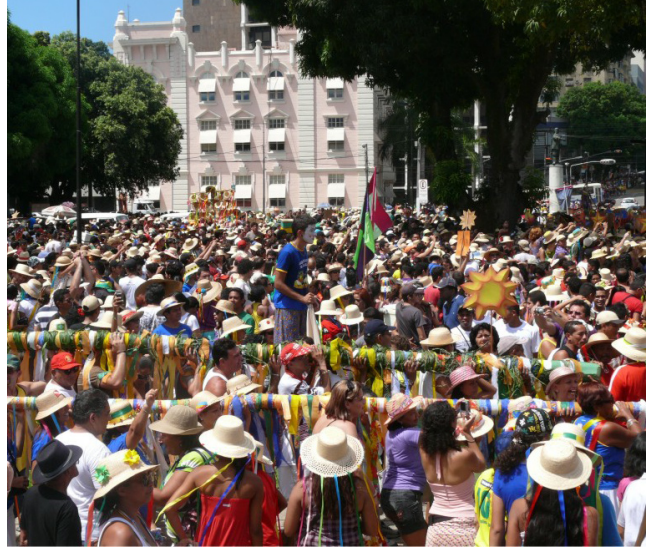

Figura 3: Os mastros inseridos no cortejo Foto Dula Lima

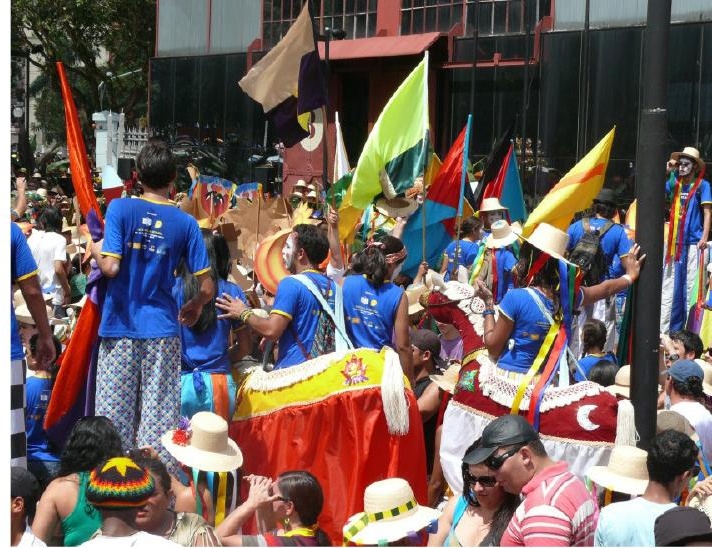

Figura 4: Cortejo junino

Foto Dula Lima

outubro, na véspera do Círio de Nazaré, é realizado o Arrastão do Círio, que homenageia essa tradição religiosa local, que leva às ruas de Belém quase três milhões de romeiros em 11 procissões, na região metropolitana de Belém (o LIBERAL, 24.10.2011). O Arrastão do Círo ocorre exatemente no final de uma dessas romarias, o Círio Fluvial. Quando a imagem da santa chega à escadinha do cais do porto, é recpcionada em festa pelo Arraial do Pavulagem, que depois da homenagem ruma pelas ruas da cidade velha até a Praça do Carmo, ponto tradicional de realização da Feira do Miriti, onde artesãos da localidade de Abaetetuba, comunidade próxima de Belém, vendem a produção anual de brinquedos temáticos confeccionados com a fibra da palmeira buçu.

Na quinzena que precede cada arrastão, o IAP passou a realizar oficinas gratuitas, abertas ao público. São modalidades de danças típicas, percussão, artes circenses (perna de pau), confecção de instrumentos, alegorias. Simultaneamente, são realizados os ensaios das músicas do período, dança e canto.

\section{CULTURA, CULTURAS}

A cultura não existe em seres humanos genéricos, em situações abstratas, mas em homens e mulheres concretos, pertencentes a este ou àquele povo, a esta ou àquela classe, em determinado território, num regime político $\mathrm{A}$ ou $\mathrm{B}$, dentro desta ou daquela realidade econômica.

Somente se poderá conceituar cultura como autorrealização da pessoa humana no seu mundo, numa interação dialética entre os dois, sempre em dimensão social. Algo que não se cristaliza apenas no plano do conhecimento teórico, mas também no da sensibilidade, da ação e da comunicação (VANNucchI, 2002, p. 21). 
O Arraial do Pavulagem retrata essencialmente essa assertiva, configurando reunião de pessoas pertencentes a diversas classes sociais, praticantes de diferentes crenças e com variadas inclinações políticas. A interação se dá no plano da sensibilidade propiciada pela afinidade com a música, a linguagem visual, o ritmo cadenciado marcado pelos símbolos e ícones ostentados orgulhosamente no vestuário, nos estandartes e nos bonecos.

$\mathrm{Na}$ verdade, o ser humano não se caracteriza, exclusivamente, como conhecedor de dados e informações culturais. Ele é também e principalmente um agente de cultura, ainda que, muitas vezes, não tenha consciência disso. E agente cultural de atividade incessante, seja caçando, para matar a fome, seja recorrendo a divindades, em oração, seja ordenhando vacas, seja operando computadores (...) são agentes de cultura tanto um lavrador como um diplomata (p. 22).

Se há dificuldade em definir cultura, ainda mais difícil é conceituar culturas. Inúmeros debates são travados sobre o que as caracteriza, qual é a mais importante, como hierarquizá-las. Vannucchi (2002) apresenta definição que ele próprio categoriza como conceito básico: “Cultura é tudo o que não é Natureza", para logo a seguir estabelecer relevante diferenciação: "Por sua vez, toda ação humana na natureza e com a natureza é cultura." E exemplifica: "a terra é natureza, mas o plantio é cultura. O mar é natureza, mas a navegação é cultura. As árvores são natureza, mas o papel que delas provém é cultura" ( $p$. 23).

No Arraial trilha-se pela epistemologia dos saberes agregados aos fazeres dos sujeitos, no processo de observar e recriar os elementos observados na natureza e expressá-los do modo único que lhes atribui sentido à existência. 0 conhecimento construído historicamente pelo sujeito. E Brandão (2002) afirma, categórico, que essa forma de fazer educação não tem na escola seu lócus único e mais adequado, que as práticas escolares podem não representar as melhores formas de se fazer educação, e que, finalmente, o professor está longe de ser o único protagonista.

Segundo Berger e Luckmann (1985), as sociedades elaboram conhecimentos dos processos sociais associados à dinâmica da natureza e da vida, e realizam as apropriações desses saberes. Nos arrastões, em seu início, os paraenses olhavam aquilo como algo exótico, quase com estranhamento, como se não fizesse parte de sua história. Eram tempos de massiva alienação cultural assimilada pela globalização. Por curiosidade, alguns assistiam, mas percebia-se a postura de quem assiste a uma apresentação folclórica como algo 
menor. Com o tempo, a familiarização com o repertório e a atração que exercia sobre os mais velhos, essa postura foi-se modificando. Pessoas começavam a cantar e dançar acompanhando os ritmos. Famílias ser reuniam nos eventos, trazendo as crianças, mostrando, ensinando sobre o que viam e ouviam. Como um redescobrir, renascer, despertar algo latente, grupos foram-se apropriando do espaço e se somando aos cortejos e shows. Da postura contida inicial, evoluiu para contagiante coadjuvabilidade. A cidade inteira se mobiliza para os eventos. Nas redes sociais, nas rádios, nos jornais, no boca a boca a notícia se espalha. Na hora marcada, pessoas chegam de todo lado, de todas as formas, e engrossam o grupo. A quantidade de participantes cresce tanto, que há alguns anos se faz necessário apoio do batalhão de trânsito e da polícia civil no sentido de resguardar qualquer ocorrência, o que, impressionantemente, não é significativo, considerando o porte da aglomeração. São eventos em que o clima de interação e alegria se sobrepõe a qualquer outro aspecto, promovido pelo sentido de pertença que emana fundamentalmente de todos.

Além do conceito básico em que afirma ser cultura tudo aquilo que não é natureza, Vannuchi (2002) categoriza cultura em diferentes conceitos: filosófico; humanista; etnológico; antropológico. No primeiro, o autor afirma que o ser humano não apenas pensa, mas reflete sobre o que pensa, e, além disso, é capaz de sentir, fazer, agir, exercer consciência espontânea e crítica, e que essas formas desse pensar-sentir, pensar-agir, constituem o objeto de suas reflexões.

Cultura, na ótica filosófica, é a forma própria e específica da existência humana no mundo. É a nossa própria existência denomenologizada, ou seja, um processo histórico permanente e inveitável, em que o ser humano tanto representa o sujeito produtivo como objeto produzido. Em suma, os homens são seres culturais por natureza (p. 24).

No conceito humanista de cultura, o autor observa que, entre as várias acepções da palavra, "é muito comum entendê-la como desenvolvimento multidimensional e harmonioso da pessoa ou da humanidade em geral, ou ainda como o acervo, bem como a transmissão espontânea ou dirigida de valores e conhecimentos".

De acordo com ele essa é a perspectiva de cultura adotada por órgãos como a Unesco, as universidades em geral, fundações e instituições oficiais de cultura, aí incluídos ministérios e secretarias.

Vannuchi (2002) estabelece conexão entre a "cultura integral" atual e a paidéia ou humanitas, que objetiva o "aperfeiçoamento pleno da pessoa, incluindo-se não apenas a educação das faculdades intelectuais, mas também 
das morais, religiosas e até mesmo corporais". Gonçalves (2009) resume a questão afirmando que o patrimônio, de certo modo, constrói, forma as pessoas.

Vannuchi (2002) discorre sobre o apogeu desse conceito ter ocorrido na Roma antiga, na relação do homem com a agricultura, ponderando que atualmente isso se percebe no culto ao corpo, no aprendizado de uma língua estrangeira, no cultivo das relações de amizade, etc. Para o autor, a visão da cultura clássica propagada e privilegiada pelas "humanidades" (homem livre e educado nas artes liberais) foi assimilada pelo cristianismo e prevaleceu na era do Renascimento, aglutinando tudo aquilo que fazia do homem um ser superior aos animais e à barbarie, e idealmente identificado a seus semelhantes. $\mathrm{Na}$ época do lluminismo, ele continua, cultura passou a ser sinônimo de "civilidade"; e, embora essa visão ainda seja adotada por muitos na atualidade, ela perdeu força como consequência do avanço científico e tecnológico e a evolução da técnica, que convivem paralelamente com processos de alienação de toda ordem. O autor explica, que na verdade, não foi a cultura humanista que perdeu crédito, mas "certa espécie de humanismo retórico, estéril, fechado em si próprio" e, por isso mesmo, como notou Sartre (1970), conduzindo tristemente ao fascismo.

No conceito etnológico de cultura, Vannuchi (2002) afirma que não existe acordo entre teóricos sobre o conceito exato de etnologia, e define cultura segundo Kroeber e Kluckonhn (1952, p. 145): “um conjunto de atributos e de produtos das sociedades humanas e do gênero humano; por conseguinte, extrassomáticos e transmissíveis por meios diferentes da hereditariedade biológica".

Em termos simples, cultura, nesse enfoque, é o modo de viver típico, o estilo de vida comum, o ser, o fazer e o agir de determinado grupo humano, desta ou daquela etnia. Fala-se assim, etnologicamente em cultura brasileira, cultura nhambiquara, cultura alemã, cultura esquimó etc. (VANNUCCHI, 2002, p. 26.).

Finalizando, o autor categoriza cultura em antropologia, afirmando que as dificuldades conceituais se acentuam sobremaneira pela divergência entre os teóricos desse campo do conhecimento. Para fins didáticos, ele apresenta quatro tendências:

1ํ) há os que veem cultura como sistema de padrões de comportamento, de modos de organização econômica e política, de tecnologias, em permanente adaptação, em vista do relacionamento dos grupos humanos com seus respectivos ecossistemas; 
2a) há os que tratam a cultura como um sistema de conhecimento da realidade, como o código mental do grupo, não como um fenômeno material, mas cognitivo;

$3^{a}$ ) há também os que encaram a cultura como um sistema estrutural, em que o eixo de tudo é a bipolaridade natureza-cultura, tendo como campos privilegiados de sua concretização o mito, a arte, a língua e o parentesco;

4a) por fim, há os que entendem cultura como sistema simbólico de um grupo humano, sistema que só poderá ser apreendido por outro grupo por meio de interpretação e não por mera descrição (p. 28).

No Arraial do Pavulagem, uma particularidade salta aos olhos que se aproximem dos arrastões: por mais que haja intenção declarada pelo Instituto Arraial do Pavulagem de valorizar e divulgar a cultura local, trabalhar a questão ambiental, a população que não milita diretamente no movimento se apropriou do espaço aberto e protagoniza outras possibilidades que inicialmente não foram pensadas, e agora são "percebidas" por seus dirigentes. A dinâmica dos eventos trouxe novas alternativas que foram naturalmente se estabelecendo, por exemplo, o forte apelo às questões de preservação do meio ambiente urbano. Nos Arrastões de junho de 2009, no carro de som, o locutor, que tem por objetivo animar e orientar a massa de brincantes, ia passando mensagens sobre a necessidade de preservação da fauna e da flora amazônicas, e pedia aos brincantes que não jogassem lixo ao longo do percurso do Arrastão apelo não atendido, como indica o volume de resíduos sólidos posteriormente recolhido. Nos arrastões de 2010 já se percebe uma apropriação desse espaço em relação a essa nova necessidade: a presença de catadores de lixo para reciclagem, devidamente identificados pelas camisetas de suas ONGs, coletando seletivamente o lixo em sacos plásticos específicos para latas e para plásticos. Membros do Arraial também se dedicaram à tarefa de ir juntando os resíduos ainda durante o Arrastão. Atrás do grupo de brincantes, garis da prefeitura acompanhavam o cortejo com carrinhos coletores e juntavam os resíduos não percebidos pelos dois grupos anteriores. Essa ação efetiva se percebe nitidamente no efeito que causa na população ainda não sensibilizada para a questão de civilidade - que preocupa mais até do que a questão ambiental e começa a gerar constrangimento, porque, quando uma pessoa joga alguma coisa no asfalto, imediatamente vem outra e recolhe o dejeto, mostrando imediatamente que aquela prática não deve existir no arrastão.

Conclui Vannucchi (2002, p. 23): "tudo o que é produzido pelo ser humano é cultura". 
Ao assumirmos como pressuposto de que a realidade humana é culturalmente construída, torna-se imprescindível reconhecermos a construção de processos sociais que se constituem no campo da cultura e da educação, por considerar que vivemos num processo de ressignificação da natureza humana... (CASTORIADIS, 1992).

Castoriadis (1992) parte da definição do homem como ser essencialmente social e histórico que convive permanentemente com a tradição, e que, no caso da cultura, a criação e a sanção das significações são sempre sociais, mesmo quando não são formalmente instituídas.

$\mathrm{O}$ homem é primeiramente psique (...), profunda e inconsciente. $\mathrm{E}$ o homem é sociedade (...) E a sociedade é sempre também história. Não há nunca, nem mesmo nas sociedades primitivas, um presente fixo. Mesmo na sociedade mais arcaica, o presente é sempre constituído por um passado que o habita e por um futuro que o antecipa. Trata-se sempre de um presente histórico (CASTORIADIS, 1992, p. 90).

Vamos, então, considerar, a seguinte definição:

Cultura é aquele todo complexo que inclui conhecimentos, crenças, arte, moral, leis, costumes ou qualquer outra capacidade ou hábitos adquiridos pelo homem como membro de uma sociedade (TYLOR, 1977).

Cultura abrange um significado fecundo e heterogêneo, que correlaciona contextos sociopolíticos diretamente ligados às dinâmicas globais e locais, e é pautada na pluralidade, na totalidade complexa. Segundo Santos (2003), "traduz-se em terreno de lutas políticas".

Brandão (2002) afirma: "o homem gera cultura na sua relação com a natureza. Cultura é história", escrita cotidianamente por grupamentos humanos diversos em diferentes lugares.

Igualdade e diferença surgem, então, como fatores a considerar quando se pensa nessa diversidade.

Todos os slogans igualitários veiculam uma ideologia totalitária. Não há diferença nos quadros sociais de qualquer sociedade que não esteja sendo operada pelo valor, como diferença de valor. $\mathrm{O}$ que se manifesta nos sinais positivos (a nossa diferença) ou negativos (a diferença dos outros) (PIERUCCI, 1999, p. 12).

$O$ respeito às características inerentes de cada cultura remete a outro conceito: o de identidade cultural. Para Hall (2002), identidades culturais têm relação com pertencimento. Para Bosi (2003), além do pertencimento ao qual está vinculada, ela é plural - global e local (tem capacidade de resistência), 
é híbrida, maleável e multicultural. O conhecimento e a apropriação das características culturais de cada grupamento humano são fatores diferenciais no estabelecimento das identidades culturais, o que fornece o instrumental para a resistência aos processos de pulverização dessas culturas pela globalização.

Ainda segundo Hall (2002), a identidade é algo formado ao longo do tempo, através de processos inconscientes, e não por algo inato, existente na consciência no momento do nascimento. Ela está sempre sendo formada.

O multiculturalismo, então, representa a tentativa de pensar um convívio diferenciado, transformando a dupla negativa diferença e distância pela dupla positiva diversidade e tolerância.

O multiculturalismo nasceu no seio das lutas dos movimentos sociais, notadamente naquelas sobre questões étnicas. Vários termos adjetivam o multiculturalismo, dependendo do teórico que aborda a questão: conservador, liberal, crítico, emancipatório, revolucionário. Também se apresentam duas abordagens: a descritiva e a prescritiva. Na primeira, predomina a concepção de ser o multiculturalismo característica das sociedades atuais, descrevendo a construção da formação multicultural de cada contexto como dado de uma realidade. Na segunda, além de ser dado de uma realidade, é uma maneira de atuar, de intervir, de transformá-la.

Encontram-se ainda outras três abordagens: 1. assimilacionista (na convivência em uma sociedade multicultural, no sentido descritivo, todos se integram e se incorporam à cultura hegemônica); 2 . diferencialista (não nega ou silencia a diferença; privilegia a formação de uma cultura homogênea); 3. intercultural (aberta à interação, com base democrática e inclusiva).

Durante a pesquisa, no Arraial do Pavulagem foi possível identificar as três abordagens. Existe a assimilação de manifestações da cultura regional por grupos diversos e multiculturais, mesmo aqueles que a desconhecem completamente, como no caso dos turistas presentes aos arrastões. Percebese ainda que as diferentes culturas presentes têm livre expressão - como no caso específico de um carioca em viagem de férias que ao frequentar os ensaios do Cordão do Peixe-boi, na tentativa de aprender o lundu, acabou criando uma terceira via entre sua intenção e o samba carioca, o que foi motivo de diversão para os espectadores. $E$, finalmente, é um espaço intercultural por excelência, porque, resguardado o cuidado de mostrar a cultura local por meio dos grupos que frequentam as oficinas e, portanto, aprendem os saberes veiculados pelo Pavulagem, e esse grupo é o que se presta a ensinar à multidão simpatizante que se agrega aos arrastões, muitas vezes sem saber nada daquilo e por observação reproduzem as coreografias e pela repetição aprendem a cantar as 
toadas, e seguem, na mesma animação, e, por gostar da experiência, retornam nos demais eventos.

Ora, a identificação de um grupo humano acontece sempre em vista de um espaço físico de origem e de certa herança histórico-cultural. O primeiro aspecto é automático e definitivo; o segundo, diferenciável e dinâmico. Assim, por exemplo, um indígena na Amazônia e um operário da Grande São Paulo nasceram ambos em chão brasileiro, mas o clima cultural de cada um difere sobremaneira (...) Todo ser humano tem raízes em uma coletividade. País e raiz, mais do que rimas, formam um par indissociável. País é o chão em que se cresce, a paisagem que nos cerca, a sociedade que nos gerou e nos envolve uterinamente. Nessa sociedade não apenas se guardam tesouros do passado, como se vivem também as indagações e os pressentimentos do futuro (VANNUCCHI, 2002, p. 43-44).

Pierucci (1999) afirma ser pré-requisito para juntar-se à turma desnudarse, "desracializar-se", despir-se de sua própria cultura. Conviver com o diverso, com a alteridade em tempos globais exercita a tolerância e permite trabalhar o fortalecimento da cultura de origem como contraponto e fator de equilíbrio nas relações.

Ninguém pode desconsiderar a força telúrica de elementos existenciais como a terra, a casa, a alimentação, a música, a dança, as crenças, o vínculo entre parentes, amigos e vizinhos, as lembranças dos idosos com suas experiências e "causos", as festas tradicionais do lugar, a língua viva, as lutas travadas, os laços de solidariedade desenvolvidos na infância... Tudo isso dá sentido e marca a gente.

Esse enraizamento, por mais embebido que esteja no ontem e por mais apoiado que se mostre no agora, longe de constituir fator reacionário, tem sido, historicamente, um dos impulsos mais vigorosos para dinamizar as virtualidades de um povo (...) pode ser sinal expressivo de uma respeitável resistência popular, ancorada num passado autêntico, porque questionante (...) Se o meio social e as condições específicas em que as pessoas vivem estão intimamente relacionados com o modo como elas percebem a si mesmas, é natural que melhor se identifica uma cultura quanto melhor se conhecem suas raízes (VANNUCCHI, 2002, p. 43-44).

Os brincantes que se juntam ao Arraial de Pavulagem fazem isso de forma espontânea, natural e com muita disposição. Nesse clima de boa vontade com o convívio, e motivados pela alegria, entoam cantigas de carimbó, lundu, polca, xote marajoara, retumbão, etc. Reproduzem passos da coreografia de cada ritmo, tudo isso em torno dos bonecos que, em cada evento, mudam a 
Figuras 5 e 6: Alegorias Cordão do Peixe-boi Fotos Dula Lima

temática, quer sejam os bois-bumbá, quer seja a imagem da santa no arrastão do Círio, quer seja em torno do peixe-boi e elementos da fauna regional. (figuras 5 e 6$)$

\section{DE TUDO FICA UM POUCO - DAS CONCLUSÕES}

Essa é a força das culturas populares - serem sempre um espécie de contabilidade à parte, cuja descoberta, apesar da fragmentação, sempre ilumina melhor, de surpresa, a empresa que todos fazemos parte. Mas daí vem também a sua fraqueza: as culturas populares, ainda que reflexo dramático de um processo de dominação e exploração, via de regra, não se politizam radicalmente. Isto é, não falam à nação, não abrangem, enquanto produção de cultura, uma ampla articulação de formas da sociedade (AGUIAR, 1977, p. 8).

$\mathrm{Na}$ análise e nos resultados dessa pesquisa, verificou-se que a força da cultura popular expressa pelo Arraial do Pavulagem exemplifica bem essa assertiva. A própria trajetória do grupo e a fala dos integrantes quando descrevem a história do arraial evidenciam fortemente o conceito desse autoproduzir articulado entre as diversas formas sociais que o compõem.

E daí decorre a convicção de que a nossa cultura popular há de se desabrochar e valorizar-se dentro de uma perspectiva libertadora, em realidades e comportamentos que concretizem o que é da experiência cotidiana e solidária do povo, muito mais ligado a fatos e pessoas do que a ideias e teorias.

Para finalizar, cumpre encarecer o notável poder de ressignificação sincrética da nossa cultura popular que, como acentuou a antropóloga Betty Milan, "não aceita as oposições clássicas, não aprisiona os símbolos atribuindo-lhes um único sentido, e por isso os reinventa" (VANNUCCHI, 2002, p. 110). 
Vannuchi (2002) fala que uma das características de nossa cultura popular é o fenômeno da apropriação de manifestações particulares de alguns de seus grupos pelo resto da sociedade, sendo até transfiguradas em símbolos no país inteiro. E cita o exemplo da feijoada, atribuída ao aproveitamento das sobras das mesas dos senhores pelos escravos e que se transformou em prato nacional, de ícone da negritude e de tensão social, depurada e manipulada como símbolo nacional. Cita, ainda, o caso da caipirinha, oriunda da roça e guindada aos ambientes sociais mais refinados. Também o samba, nascido nos morros cariocas, identificado inicialmente como coisa de malandro, para depois ser glorificado como expressão musical tipicamente brasileira e virar produto nacional de exportação.

Santos (2003) afirma que as pessoas e os grupos sociais têm o direito de ser iguais quando a diferença os inferioriza, e o direito de ser diferentes quando a igualdade os descaracteriza. Com essa máxima, definimos a abordagem intercultural como caminho nesta pesquisa. A investigação qualitativa, etnográfica foi realizada no período de dois anos, seis arrastões, utilizando coleta de dados em documentos, publicações, arquivos digitais e vídeos, entrevistas semiestruturadas e registro fotográfico. Como resultado foi constatada a eficácia na transmissão de elementos culturais inerentes ao patrimônio imaterial da cultura amazônica assimilados por um grupo heterogêneo em faixa etária, gênero e características socioeconômicas por adesão, simpatia e identificação em pertença com formas, sons, movimentos, gestual e alegorias. Atração por sedução. Educação pela alegria. Assimilação por identidade cultural.

E nos caminhos do arrastão encontramos a heterogeniedade de sujeitos sociais, uma amostra substantiva da diversidade humana global, seguindo um boizinho azul, dançando e cantando num momento de igualdade que encanta os olhos e o coração, sob o sol, sob a chuva, na via de asfalto quente, por entre o túnel de mangueiras de Belém, sob a égide do equador.

\section{REFERÊNCIAS BIBLIOGRÁFICAS}

AGUIAR, Flávio. Artistas e festas populares. São Paulo: Brasiliense, 1977.

BERGER, Peter L; LUCKMANN, Thomas. A construção social da realidade. Tradução de Floriano Fernandes. Petrópolis: Vozes, 1985.

BOSI, A. (Org.). Cultura brasileira. Temas e situações. São Paulo: Ática, 2003.

BRANDÃO, Carlos Rodrigues. A educação como cultura. Campinas: Mercado de Letras, 2002.

CASTORIADIS, Cornelius. O mundo fragmentado: as encruzilhadas do labirinto III. Tradução Rosa Maria Boaventura. 2. ed. Rio de Janeiro: Paz e Terra, 1992. 
GONÇALVES J. O patrimônio como categoria de pensamento. In: ABREU, Regina; CHAGAS, Mario (Org.). Memória e patrimônio. Rio de Janeiro: DP\&A, 2009. p. 21-29.

HALL, Stuart. A identidade cultural na pós-modernidade. 7. ed. Rio de Janeiro: DP\&A, 2002.

KROEBER, A.L.; KLUCKHOHN, C. Culture: A critical review of concepts and definitions. V.XLVII, N.1 Papers of the Peabody Museum of American Archeology and Ethnology Papers, Harvard University. 47,1, 1952.

PIERUCCI, Antonio Flávio. Ciladas da diferença. São Paulo: Editora 34, 1999.

SANTOS, Boaventura de Souza (Org.). Reconhecer para libertar: os caminhos do cosmopolitismo multicultural. Rio de Janeiro: Civilização Brasileira, 2003.

SARTRE, J. P. O existencialismo é um humanismo. Lisboa: Presença, 3. ed, 1970.

TYLOR, Edward B. (1871) Primitive culture: Researches into the development os mythology, philosophy, religion, art and custom. Vol. I. London: John Murray, 1977.

VANNUCCHI, Aldo. Cultura brasileira: como é, como se faz. São Paulo: Loyola, 2002.

\section{NOTA}

1 Alegoria de mão, sustentada por uma tala de madeira.

Dula Maria Bento de Lima é professora adjunta I da Universidade da Amazônia (Unama). Mestra em educação (Uepa), doutoranda em design pela Universidade do Porto, pesquisadora do Núcleo de Pesquisa Qualidade de Vida e Meio Ambiente da Unama e do Núcleo Sociedade, Ciência e Ideologia da Uepa/CNPq. Email: dulalima@gmail.com

Estélio Gomberg é professor adjunto I da Universidade Estadual de Santa Cruz (Uesc). 
